doctor has not diagnosed angina should have electrocardiography. Measurement of blood cholesterol concentration in the high risk subjects should be considered because lowering concentrations and monitoring dietary change are most desirable in this group. Measurement of cholesterol concentration is particularly indicated in subjects who have had coronary artery bypass grafting or angioplasty, in whom a low concentration is essential.

Simple plastic discs for help in adding up the score have been produced by Lederle Laboratories, Gosport, Hampshire PO13 0AS, and by Servier Laboratories, Fulmar, Slough SL3 7HH. A programmed calculator has also been produced by INFOLOG, Time Master Systems, Barclay House, 35 Whitworth Street West, Manchester M1 5NG, which allows scoring systems to be used that include electrocardiographic findings and blood cholesterol concentrations.

A G SHAPER MARY WALKER

Department of Public Health and Primary Care,

Royal Free Hospital School of Medicine,

London NW'3 $2 \mathrm{PF}$

1 Tunstall-Pedoe $\mathrm{H}$. The Dundee coronary risk-disk for management of change in risk factors. B.117 1991;303:744-7. 28 September.

Working (iroup of the Coronary Prevention Group and the British Heart Foundation An action plan for preventing coronary heart disease in primary care. B.MI 1991:303:748-50. (28 September.

3 Shaper AG, Pocock SJ, Phillips AN, Walker M. A scoring system to identify men at high risk of a heart attack. Health Trends 1987:19:37-9.

\section{Increased sensitivity of dopamine receptors in puerperal psychosis}

SIR,-In A Wieck and colleagues' paper on increased sensitivity of dopamine receptors and recurrence of affective psychosis after childbirth the presentation of results is misleading because the figure showing the individual growth hormone response curve does not show that the patients with the two highest responses were suffering from depression (as reported by one of the authors ( $\mathrm{R}$ Kumar) in public presentations of the work). These depressed patients may or may not have been suffering from a recurrence of an affective psychosis.

There is no agreement that mothers who meet Research Diagnostic Criteria for major depression within 90 days after childbirth-possibly up to $10 \%$ of all puerperal women-are suffering from the same phenomenon as puerperal psychosis, which complicates $0 \cdot 2 \%$ of deliveries. It was not justifiable to include these patients without giving details of the clinical picture and the timing and the circumstances of the illness. With such a small series of patients suffering from a variety of psychiatric disorders and showing a wide variance of growth hormone responses it would have been appropriate to include a table with individual results and a clinical summary.

The most important datum to emerge from this study is that patients who have already begun to suffer a puerperal psychosis show virtually no response of growth hormone to challenge with apomorphine. This was true of two of the four patients who had prodromal symptoms at the time of the test, and this fact is also buried in the results, which report only the mean concentrations in these four women. We have also encountered a mother with a minimal growth hormone response on day 4 and day 11 after delivery who developed a manic illness judged to have begun on day 10 (she later developed postpartum thyrotoxicosis).

The finding that some patients in the early stages of a puerperal psychosis have nugatory growth hormone responses is hard to reconcile with the hypothesis that supersensitivity of dopamine receptors is an important factor in this disease.

\section{F BROCKINGTON}

C J MEAKIN

Department of Pyschiatry,

Hospital,

Birmingham $\mathrm{B} 152 \mathrm{QZ}$

\section{W'ieck A, Kumar R, Hirst AD, Marks MN, Campbell IC, Checkley $S A$. Increased sensitivity of dopamine receptors and recurrence of affective psichosis after childbirth. B.M7 1991:303:613-6. 1+ September.}

Authors' REPLy,-I F Brockington and C J Meakin query our inclusion of two women who suffered episodes of major depressive disorder in our subgroup of subjects who experienced a relapse of affective psychosis. Women who have definite histories of bipolar manic-depressive illness or of schizoaffective psychosis and who then become depressed after delivery may not be typical of the $10 \%$ or so of women without such histories who become depressed postnatally. Of the two depressed mothers to whom Brockington and Meakin refer, one just failed to meet operational criteria for hypomanic disorder after delivery and the other quite unexpectedly and impulsively attempted to kill her 8 week old infant. Despite careful inquiry we were unable to ascertain whether this act was, for example, in response to a false belief or a command hallucination, and we therefore reported her only as suffering from major depression.

At the public presentations mentioned we have also reported preliminary data on seven women with histories of unipolar, major depression. One of them developed a major depression and another panic disorder shortly after delivery, but none of this group had increased growth hormone responses to apomorphine. Our preferred strategy is to investigate rather than to presuppose knowledge of putative sites of cleavage between different kinds of affective disorder before and after childbirth. On rechecking our paper, however, we have come across an error that we should like to correct. In the fourth paragraph of the results section the penultimate sentence should read: "Of the two women who had a late onset ( $\geqslant 6$ weeks) of illness, one had an increased growth hormone response and one did not,"

We, too, were intrigued by the lack of any clear link between the presence of possible prodromal symptoms and the size of the growth hormone response. We therefore described the data in considerable detail (in the second and fifth paragraphs of the results section). Finally, our figure giving the growth hormone curve for each subject clearly shows that there were two false negatives and one false positive in the high risk group, and it is not obvious to us what additional point Brockington and Meakin are making by referring to their own single case study of a similarly tested mother.

R KUMAR A WIECK A D HIRST M N MARKS C CAMPBELL S A CHECKLEY

\section{Institute of Psychiat}

London SE5 $8 \mathrm{AF}$

I Wieck A, Kumar R, Hirst AD, Marks MN, Campbell IC, Checkley SA. Increased sensiticity of dopamine receptors and recurrence of affective psychosis after childbirth. BMY 1991;303:613-6. 1+ September.

\section{Community care for patients with schizophrenia}

SIR,-David Melzer and colleagues found that among their sample of patients with schizophrenia interviewed one year after discharge from hospital $52 \%$ had attended a psychiatric outpatient department in the previous three months while $57 \%$ had seen their general practitioner. It seems that general practitioners were at least as likely as psychiatrists to be concerned in the patients' medical supervision.

It is interesting to compare these findings with those of Murray-Parkes et al in $1962^{2}$; they followed up 100 patients with schizophrenia for a year after discharge, also in London, and found that $56 \%$ attended psychiatric outpatients departments while $70 \%$ saw their general practitioners. They concluded that general practitioners saw the patients much more commonly than did psychiatrists, provided most of the prescriptions, and were the principal people concerned in initiating fresh treatment and rearranging readmission when the patient relapsed. The situation seems to have changed little in 30 years despite the policy of providing for the needs of psychiatric patients in the community, embodied in a white paper of 1975.

A considerable minority of general practitioners, notably those in city practices, have suffered an increased workload owing to the increased number of long term mentally ill patients living outside hospitals, ${ }^{4}$ yet they do not seem to have much more help from community psychiatric teams than do general practitioners with fewer such patients.

The role of general practitioners in the care of patients with disorders such as schizophrenia is inevitable, but they need support from specialist services. Only a third of general practitioners have any postgraduate training in psychiatry. General practitioners could identify long term mentally ill patients on their lists who might benefit from increased contact with psychiatric services Planners should identify practices with more than their share of such patients and target community psychiatric resources to the areas of greatest need.

St (ieorge's Hospital Medical School TONY KENDRICK

London SW'17 ORE

1 Melzer D, Hale AS, Malik SJ, Hogman (GA, Wood S. Community care for patients with schizophrenia one vear after hospital discharge. B.MF 1991:303:1023-6. (26) ()ctober

2 Murray-Parkes C, Brown GW, Monck EM. The general practitioner and the schizophrenic patient. BMJ 1962;i:972-6. 1) epartment of Health and Social Security. Better services for the mentally ill. London: HMSO, 1975.

+ Kendrick T, Sibbald B, Burns T, Freeling P. Role of general practitioners in care of long term mentally ill patients. $B M \mathcal{F}$ 1991:302:508-10.

SIR,-David Melzer and colleagues report on the poor social adjustment and psychotic mental state of many people with schizophrenia one year after discharge from hospital.' Things need not be like this and could be changed, given determination and sufficient resources. It was therefore depressing to read in the same issue that when asked to rank a variety of health targets a group of administrators and doctors put community care for people with schizophrenia far down their list of priorities, behind family planning and surfactant treatment for neonates

The role of general practitioners in managing patients with chronic mental illness is frequentiy understated. In the United States a survey showed that a quarter of all such patients' contacts were with primary care physicians as compared with a half with psychiatrists. ${ }^{3}$ Melzer and colleagues' figures show that the general practitioner was the professional or service most commonly contacted by people with schizophrenia, $57 \%$ of those surveyed having seen their general practitioners at least once during the previous three months.' In comparison $52 \%$ had attended a psychiatric outpatient department and only $8 \%$ had been in contact with a day hospital. Community psychiatrists have sought to transfer the care of people with schizophrenia from hospitals to dav hospitals and outreach services while retaining overall responsibility for their care. The reality is that such patients will nevertheless seek help most frequently from their general practitioner

The World Health Organisation said that "the 